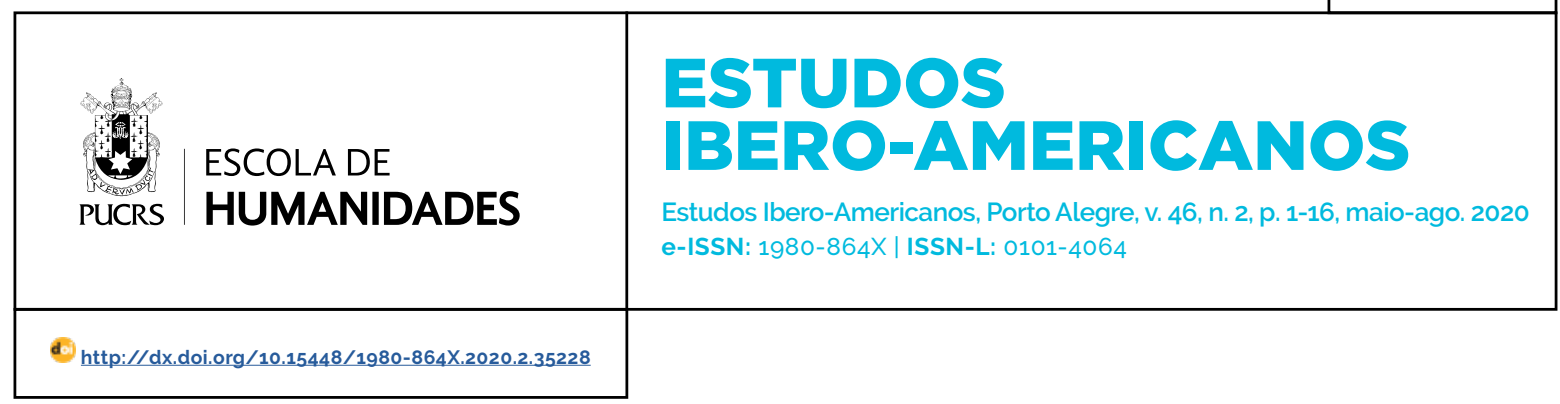

SEÇÃO: DOSSIÊ IMPRENSA, CULTURA E CIRCULAÇÃO DE IDEIAS

\title{
Pensamento político e imprensa brasileira no pós-guerra: democracia e participação popular na visão do Correio da Manhã no Segundo Governo Vargas
}

\author{
Political thought and the Brazilian press in the post-war period: democracy and popular \\ participation in the view of Correio da Manhã in the Second Vargas Government \\ Pensamiento político y la prensa brasileña en el periodo de posguerra: democracia y \\ participación popular en la opinión de Correio da Manhã en el Segundo Gobierno de Vargas
}

\section{Luís Carlos dos Passos}

Martins $^{1}$

orcid.org/0000-0002-7564-4092

luis.martins@pucrs.br

Recebido em: 03 ago. 2019. Aprovado em: 16 jan. 2020. Publicado em: 25 ago. 2020.

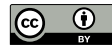

Artigo está licenciado sob forma de uma licença Creative Commons Atribuição 4.0 Internacional.
Resumo: O presente artigo irá abordar um tema ainda pouco explorado pela historiografia: o pensamento político da grande imprensa brasileira no "periodo democrático" do pós-guerra (1946 a 1964). Análises acerca do posicionamento político dos principais jornais do Pais são bastante frequentes. Todavia, tais trabalhos dedicam-se majoritariamente a procurar identificar a filiação político-partidária dos periodos e as possiveis estratégias de "manipulação de informações". Em alguns casos, encontramos pesquisas que se dedicam às preferências ideológicas dos impressos, mas, mesmo aqui, prepondera o princípio segundo o qual os jornais seriam apenas reprodutores dos interesses dos grupos e/ou classes sociais que os controlariam. Contrariando essa tendência geral, nosso artigo pretende explorar a visão do jornal Correio da Manhã sobre a democracia politica brasileira durante o Segundo Governo Vargas (1951-1954). Nossa intenção não está em identificar o posicionamento do referido periódico sobre a gestão de Getúlio, já bastante explorado pela historiografia. Pretendemos, ao contrário, a partir dos argumentos empregados para avaliar o regime democrático, apresentar o diagnóstico negativo que esse importante impresso carioca faz desse regime, indicando, ainda nos anos 1950, seu frágil comprometimento com as instituições democráticas vigentes. Como chave de leitura sobre esse posicionamento, iremos relacionar a visão do jornal em seus espaços de opinião com as ideias do pensador Azevedo Amaral sobre a politica brasileira nos anos 1920-1930. Recorde-se que Amaral foi importante articulista e editor do Correio e teve grande influência sobre os seus principais jornalistas, notadamente Pedro Costa Rêgo, editor do jornal no período estudado.

Palavras-chave: Vargas. Imprensa. Pensamento político.

Abstract: This article will address a topic still little explored by historiography: the political thinking of the Brazilian press in the post-war "democratic period" (1946-1964). Analyzes about the political positioning of the main newspapers of the country are quite frequent. However, such works are mainly devoted to identifying the partisan political affiliation of the periods and the possible strategies of "information manipulation". In some cases, we find research that focuses on the ideological preferences of print, but even here, the principle that newspapers are only reproducers of the interests of the groups and / or social classes that would control them prevails. Contrary to this general trend, our article aims to explore the newspaper Correio da Manhã's view of Brazilian political democracy during the Second Vargas Government (1951-1954). Our intention is not to identify the positioning of this journal on Getúlio's management, already well explored by historiography. On the contrary, we intend, based on the arguments used to evaluate the democratic regime, to present the negative diagnosis that this important carioca print makes of this regime, indicating, even in the 1950s, its fragile 
commitment to the existing democratic institutions. As a key reading about this position, we will relate the newspaper's view in its spaces of opinion with the ideas of thinker Azevedo Amaral about Brazilian politics in the 1920-1930s. Remember that Amaral was an important writer and editor of the Courier and had a great influence on its main journalists, notably Pedro Costa Rêgo, editor of the newspaper during the period studied.

Keywords: Vargas. Press. Political thought.

Resumen: Este artículo abordará un tema aún poco explorado por la historiografía: el pensamiento político de la prensa brasileña en el "período democrático" de posguerra (1946-1964). Los análisis sobre el posicionamiento político de los principales periódicos del país son bastante frecuentes. Sin embargo, tales trabajos se dedican principalmente a identificar la afiliación política partidista de los periodos y las posibles estrategias de "manipulación de la información". En algunos casos, encontramos investigaciones que se centran en las preferencias ideológicas de la impresión, pero incluso aqui, prevalece el principio de que los periódicos son solo reproductores de los intereses de los grupos y / o clases sociales que los controlarian. Contrariamente a esta tendencia general, nuestro articulo tiene como objetivo explorar la opinión del periódico Correio da Manhã sobre la democracia política brasileña durante el Segundo Gobierno de Vargas (1951-1954). Nuestra intención no es identificar el posicionamiento de esta revista en la gestión de Getúlio, ya bien explorada por la historiografia. Por el contrario, pretendemos, con base en los argumentos utilizados para evaluar el régimen democrático, presentar el diagnóstico negativo que esta importante impresión carioca hace de este régimen, indicando, incluso en la década de 1950, su frágil compromiso con las instituciones democráticas existentes. Como lectura clave sobre esta posición, relacionaremos la visión del periódico en sus espacios de opinión con las ideas del pensador Azevedo Amaral sobre la politica brasileña en los años 20-30. Recuerde que Amaral fue un importante escritor y editor del Courier y tuvo una gran influencia en sus principales periodistas, especialmente Pedro Costa Rêgo, editor del periódico durante el período estudiado.

Palabras clave: Vargas. Prensa. Pensamiento político.

\section{Introdução}

O presente artigo procura avançar as pesquisas desenvolvidas por mim sobre a grande imprensa brasileira e a "circulação das ideias políticas" no período de 1946 a 1964. Para dar continuidade a este trabalho, pretendo aqui testar com mais acuidade a hipótese sobre a aproximação da visão do Correio da Manhã a respeito do regime democrático no Brasil durante o Segundo Governo Vargas e algumas proposições sustentadas pelo chamado "pensamento autoritário" brasileiro, representado aqui pela obra de Azevedo Amaral. Este autor, durante os anos de 1920 e 1930, foi articulista e editor do jornal, sendo amigo e inspirador intelectual do jornalista e político Costa Rego, que assumiu a editoria do Correio depois da saída de Amaral.

Com o objetivo traçado acima, irei, inicialmente, tecer algumas considerações sobre o conceito de democracia; em um segundo momento, farei uma análise da concepção de Azevedo Amaral sobre a democracia política no Brasil e, por fim, exercitarei uma comparação, embora parcial devido ao estágio inicial de investigação, com a percepção a respeito deste tema presentes nas páginas editoriais do Correio da Manhã nos anos 1950.

\section{Democracia, o nome, a coisa}

Democracia é uma daquelas palavras cujo amplo emprego corresponde a uma igualmente vasta polissemia, em especial, quando esse uso transita do discurso acadêmico à discussão política. Um levantamento, mesmo que superficial, dos diversos sentidos com os quais esse termo é empregado seria, dessa forma, extenso e incompleto. Em consequência, para o meu propósito, irei fazer um recorte específico procurando salientar, mesmo que parcialmente, como esse conceito é definido e apropriado na legitimação dos sistemas políticos classificados como democráticos na Era Moderna.

Em termos institucionais, a partir do século XVIII e, notadamente, do século XIX, as sociedades modernas apropriaram-se do termo gre-

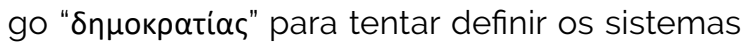
políticos que estavam sendo implantados nos EUA e na Europa com a ampliação do direito do voto, ainda que mulheres, analfabetos e, em alguns casos, pobres permanecessem excluidos. Todavia, esse processo provocou transformações na definição original do conceito de democracia, implicando em fortes mudanças nos procedimentos necessários para se classificar um regime como democrático em comparação com o mundo antigo. Norberto Bobbio sintetizou bem essa questão ao salientar que uma das principais diferenças entre a democracia antiga e a moderna estava no fato de que a primeira pressupunha a participação direta dos cidadãos nas instâncias decisórias, como assembleias e conselhos, enquanto a segunda facultava este exercicio a representantes eleitos (BOBBIO, 2000). 
Nunca é demais recordar, porém, que tal mudança esteve longe de ser simples, pois implicou, além das transformações econômicas e sociais que lhe deram base material, profundas modificações conceituais. Com efeito, enquanto a Cidade-Estado grega não estabelecia uma separação formal entre o corpo de cidadãos e a sua representação política em instituições ou organismos "públicos", 2 a democracia dos modernos baseou-se no conceito de representação. Foi o pensador liberal Benjamin Constant quem melhor apresentou essas distinções. ${ }^{3}$ Em 1819, em um texto que se tornaria clássico - De la liberté des anciens comparée à celle des modernes -, o autor, procurando traçar as principais diferenças entre a "liberdade" dos antigos e a dos modernos, defendeu que a primeira, embora válida em seu tempo, não era mais adequada e nem mesmo desejada para os "modernos". Segundo ele, as dimensões do Estado-Nação contemporâneo e a sua organização econômica e social (fim da escravidão, desenvolvimento do comércio) tiraram o tempo livre que os cidadãos poderiam destinar aos negócios do Estado e tornaram a sua vida privada mais interessante do que os assuntos públicos. ${ }^{4}$ Diante deste quadro, Constant concluiu pela necessidade de uma nova concepção de liberdade definida por ele como "as garantias concedidas pelas instituições" aos interesses e aos privilégios privados (1985, p. 16). Já a participação política mediante o "sistema representativo", segundo suas palavras,

[...] não [era] mais que uma organização com a ajuda da qual uma nação [confiava] a alguns individuos o que ela não pode ou não quer fazer. [...] O sistema representativo é uma procuração dada a um certo número de homens pela massa do povo que deseja ter seus interesses defendidos e não tem, no entanto, tempo para defendê-los sozinho (CONSTANT, 1985, p. 23, grifo nosso).
Em outras palavras, a democracia moderna, para o autor, era tributária de um conceito com o qual praticamente se confundia, ou seja, o de representação. Este conceito, todavia, não nunca foi isento de controvérsias e o acolhimento de uma definição está diretamente ligado ao tipo de "representação política" que se pretende instituir, com maior ou menor participação popular. Logo, representação não é um processo simples, implicando, em boa parte das vezes, em escolhas sobre a melhor e/ou mais eficaz forma de presentificar o ausente. ${ }^{5}$ No caso da representação política, esta situação acarreta desafios constantes. Um deles está na questão já colocada por Hobbes no Leviatã sobre como é possivel alcançar a expressão de uma vontade coletiva em assuntos públicos a partir de vontades individuais diferentes e, por vezes, divergentes no corpo de cidadãos comuns? A resposta de Hobbes - segundo a qual apenas a unidade do representante tem condições de expressar a unidade dos representados individuais ${ }^{6}$ - pode parecer muito drástica aos olhos contemporâneos, mas ela coloca, em seus limites, um dilema básico de todo o sistema representativo, qual seja: o papel do representante não apenas substituindo o representado, mas, também, constituindo-o publicamente na medida em que ele pode se tornar a sua única expressão visivel e legítima.

No caso das democracias representativas, como salienta Constant, a principal alternativa para dar conta dessa situação foi conceber o representante como um mandatário do representado, mas dotado de uma procuração para falar em seu nome limitada no tempo e na amplitude dos seus atributos. Disso decorre que o bom funcionamento da democracia representativa depende não só da necessidade de o representante prestar contas

\footnotetext{
Como ressalta MOSSÉ, a assembleia de cidadãos (ecclesia), onde se exercia a soberania popular, não era uma instituição separada "mas o povo reunido e teoricamente, pelo menos, todo o cidadão ateniense tinha, não apenas o direito, mas o dever de assistir as sessões" (Mossé, 1985, p. 49).

3 Refiro-me à conferência Da liberdade dos antigos comparada à liberdade dos modernos. As citações neste artigo foram retiradas da seguinte publicação: Constant, 1985.

4 Na época moderna, afirma Constant, "(o) exercício contínuo dos direitos políticos [...] acarretaria apenas perturbação e cansaço às nações modernas, onde cada individuo, ocupado em suas especulações, por seus empreendimentos, pelos resultados que obtém ou espera, quer ser desviado disso o menos possivel" (1985, p. 14).

5 Como lembra Hanna Pitkin, representação, por definição, implica em uma substituição "simbólica" de algo que, por principio, não está - e/ou não pode estar - "presente" em determinadas condições espaço-temporais, sendo normalmente empregada em circunstâncias nas quais ela é necessária e/ou vantajosa" (PITKIN, 2006, p. 18).

6 Que podemos ilustrar com a expressão - por sinal, diversas vezes citada - de Hobbes: "é a unidade do representante, e não a unidade do representado, que faz a pessoa ser una" (HOBBES, 2003, p. 141). Sobre este tema, consultar: OSTRENSKY, 2010.
} 
aos representados, mas também da capacidade do representado em fazer uma boa avaliação das ações que o representante realiza na direção da coletividade. Em outras palavras, uma democracia representativa legitima pressuporia um cidadão minimamente ativo que, mesmo não participando diretamente do exercício do poder, esteja apto para escolher bem seus mandatários e para acompanhar as suas atuações na esfera decisória.

Esse tema é tão crucial que o risco ao sistema democrático derivado da ausência desse cidadão foi objeto de preocupação de dois dos principais teóricos do século XIX da democracia representativa: Alex de Tocqueville (A Democracia na América, 1832) e, posteriormente, John Stuart Mill (Sobre a Liberdade, 1859, e Considerações sobre o Governo Representativo, 1861). Para ambos, um dos maiores perigos das democracias modernas era a tendência à apatia do cidadão comum como um efeito colateral do sistema representativo. Envolto em tarefas cotidianas direcionadas à busca pela sobrevivência material, as quais apresentariam um caráter eminentemente repetitivo, o homem "médio" das sociedades modernas tenderia a atrofiar o seu senso crítico sobre os assuntos coletivos. Isso o tornaria propenso a abandonar a administração do Estado em favor dos governantes e, assim, permitir a emergência de uma nova forma de despotismo. Como recorda Tocqueville, finalizando sua argumentação sobre o tema: "O que é importante combater, portanto, é muito menos a anarquia ou o despotismo do que a apatia, que pode criar quase indiferentemente um ou outro" (TOCQUEVILLE, 200, p. 418).

Para ambos os autores, só haveria uma alternativa à tendência ao governo despótico nos regimes democráticos: a mobilização constante dos cidadãos nos assuntos públicos, cujo principal instrumento era a liberdade de expressão e de impressão das suas ideias políticas, o que foi muito bem enfatizado na obra Sobre a Liberdade, de Mill. Todavia, é importante ressaltar que esse processo de mobilização não seria resultado da mera espontaneidade dos cidadãos individuais e isolados, mas sim do trabalho corpos intermediários entre o corpo cívico e o Estado - não apenas partidos, mas associações de todo o tipo, capazes de (re)acender no cidadão comum o seu interesse pela vida coletiva. Como lembra Tocqueville em A Democracia na América: "Em nosso tempo, a liberdade de associação tomou-se uma garantia necessária contra a tirania da maioria" (TOCQUEVILLE, 2000, p. 223).

Este tema foi muito bem trabalhado por Habermas no conceito de esfera pública burguesa (Mudança Estrutural na Esfera Pública, 1984). Buscando inspiração em Kant, Habermas define essa esfera como uma instância que, através da "opinião pública", intermediaria as relações entre o "Estado e as necessidades da sociedade" (1984, p. 47). Segundo o filósofo frankfurtiano, tal espaço - emergido entre os séculos XVII e XVIII nas sociedades capitalistas modernas - pertenceria obrigatoriamente ao universo do privado, sendo constituído por pessoas privadas enquanto público e não estaria ligado ao poder do Estado, instituindo-se contra ele (HABERMAS, 1984, p. 43). Todavia, para exercer a sua função crítica, a esfera pública burguesa deveria ser composta por homens instruidos e livres, tanto da dependência do Estado, quanto das necessidades materiais imediatas, caso contrário, tais individuos não se tornariam um público. Essa era uma condição necessária para que estes "homens" pudessem se dedicar ao debate "racional" sem a interferência da pressão do governo ou de seus próprios interesses particulares, tornando-se expressão da Razão Universal (1984, p.51). Composta desta forma, essa esfera proporcionaria o espaço institucional capaz de produzir aquilo que os filósofos das Luzes classificaram, segundo o autor, como opinião pública esclarecida - que não pode ser confundida com a opinião do público geral. Esta opinião, todavia, pelas altas exigências culturais de acesso, acabou se tornando um atributo das elites letradas.

Todavia, no século XIX, tanto a esfera pública, quanto o conceito de opinião pública iriam sofrer uma forte mudança de sentidos em direção àquilo que, para Rosanvallon, constitui o caráter revolucionário da democracia política contemporânea, a saber, a instituição do voto universal. Como bem salienta o autor, o estabelecimento desta forma de voto pressupõe uma igualdade e uma equivalência 
política de todos os cidadãos, independentemente das suas condições econômicas e educacionais. ${ }^{7}$

Essa mudança de perspectiva sobre a inclusão política e o direito ao voto não ia ficar sem consequências sobre a concepção de opinião pública e de todas as suas implicações frente ao funcionamento da democracia representativa. Ainda conforme Habermas, a própria aceitação de termo opinião pública como uma expressão adequada para dar conta do debate necessário à aprovação (ou não) dos assuntos coletivos motivou forte controvérsia. Contra ela pesava uma longa tradição filosófica - que podemos remontar no mínimo a Platão -, segundo a qual a opinião (doxa) seria uma forma menor e até inadequada de expressão de pensamento, especialmente quando contrastada com o raciocinio e a Razão. Desta forma, não deve surpreender que a passagem de concepção da opinião pública como opinião esclarecida para opinião da maioria implicou em uma verdadeira "revolução" conceitual em termos político equivalente à aceitação do voto universal. Os autores que tratam do tema, porém, têm dificuldade de localizar os suportes textuais que deram corpo a esta mudança, na medida em que tudo leva a crer, como bem salientou Rosanvallon, que ela se operou no debate político (parlamentar/jornalístico) e não nas querelas filosóficos. Essa transição da opinião pública como opinião esclarecida em direção à opinião da maioria não deixou de preocupar os filósofos e pensadores que refletiam sobre as bases dos regimes democráticos no século XIX. Com efeito, Alexis de Tocqueville e Stuart Mill identificaram na prevalência da opinião da maioria e na sua capacidade de impor, via sistema eleitoral, seus interesses específicos sobre todos os demais, o maior perigos dos regimes representativos, a saber, a tirania das maiorias. Sobre esse risco, Stuart Milljá nos alerta no seu ensaio Sobre a Liberdade:

\begin{abstract}
Suponhamos, pois, que o governo esteja em inteira harmonia com o povo, e nunca pense em exercer qualquer poder coercitivo senão de acordo com o que the parece a voz deste. Eu nego, porém, o direito do povo de exercer essa coerção, por si mesmo ou pelo seu governo. Tal poder é ilegitimo em si. O melhor governo não tem a ele título superior ao do pior. É tão nocivo, ou ainda mais, nocivo, quando exercido de acordo com a opinião pública, ${ }^{8}$ do que em oposição a ela (MILL, 2007, p. 43).
\end{abstract}

De qualquer maneira, independentemente da força argumentativa desses dois autores, o ponto é que, conforme apontou Champagne, na virada do século XIX para o XX, a opinião pública entendida como a opinião do maior número ${ }^{9}$ havia se tornado um lugar comum na discussão política, cuja legitimidade como instância de poder dificilmente poderia ser contestada sem grandes resistências (CHAMPAGNE, 1990).

De toda essa discussão, interessa-nos especialmente ressaltar que as querelas em torno da organização política nas sociedades modernas passam necessariamente: a) pela discussão sobre a melhor forma de representação da comunidade política nas esferas decisórias do poder e b) pelo papel da opinião pública na relação entre representantes e representados. É uma discussão acima de tudo acerca de qual representação política é a mais adequada para tornar legítimas e eficazes as ações dos representantes em nome dos representados. Por fim, no caso da democracia representativa, a adoção do voto universal, se consolidou as ideias de equivalência política entre todos os cidadãos livres e da existência de uma sociedade formada por individuos independentes e atomizados, a participação política ativa implicou em aceitar que a mobilização desses cidadãos em corpos intermediários é uma condição necessária para que suas opiniões dispersas ganhem forma e força nas decisões públicas.

\footnotetext{
7 Nas palavras de Rosanvallon, a instalação do voto universal "afirma um tipo de equivalência de qualidade entre os homens, em completa ruptura com as visões tradicionais do corpo político. Ela apenas se forma no horizonte de uma visão atomística e abstrata da formação da ligação social. A igualdade política, em outros termos, é apenas pensável na perspectiva de um individualismo radical, em contraposição às outras formas de igualdade que podem perfeitamente se acomodar em uma organização hierárquica ou diferenciada do social (1992, p. 14-15).

8 A opinião pública condenável aqui é essa opinião da maioria que, para Mill, era a "opinião da mediocridade": "Aqueles cujas opiniões se conhecem pelo nome de opinião pública, não são sempre o mesmo público; na América, são o conjunto da população branca, na Inglaterra, principalmente a classe média. Entretanto, são sempre uma massa, isto é, mediocridade coletiva" (MILL, 2007, p. 118).

9 Obviamente que, na maioria dos casos, excluindo deste maior número mulheres e analfabetos.
} 


\section{Azevedo Amaral e a democracia impossibilitada}

O termo e o tema da democracia foram muito recorrentes na obra de Azevedo Amaral, aparecendo desde os seus primeiros escritos até em seu livro mais conhecido (O Estado Autoritário e a Realidade Nacional), publicado já durante o Estado Novo. Todavia, apesar da constância de sua presença, há de se ressaltar que a abordagem do autor sobre a questão está longe de ser linear ou isenta de tensões e reposicionamentos. Acima de tudo, democracia era uma palavra que Amaral demonstrou frequente necessidade de lidar, mesmo criticando ou ressignificando seu conceito. Deve-se, todavia, salientar que, na maioria das vezes, Azevedo Amaral se referia à democracia acompanhada do adjetivo "liberal" e frequentemente substitua a expressão "democracia liberal" por "sistema representativo com voto promíscuo". Tais opções não são gratuitas e deixam transparecer que o escritor carioca está pensando em uma variedade possivel, embora não necessária, de democracia definida como um sistema representativo baseado no "voto promiscuo", ou seja, no voto universal no qual todas as opiniões seriam equivalentes e os eleitores votariam independente de qual grupo (étnico, social, econômico etc.) pertençam no mundo social.

Em convergência com outros escritores classificados como autoritários no Brasil, durante as décadas de 1920 e de $1930,{ }^{10}$ Amaral identificava a democracia liberal no Brasil como uma "ideia fora do lugar", ou seja, como um conceito político que, independentemente dos seus méritos originais, era inadequado à realidade brasileira. Ao fazer isso, Amaral objetivava atacar o pressuposto supostamente liberal ${ }^{11}$ segundo o qual determinadas instituições políticas - como o sufrágio universal e o regime parlamentar - teriam validade universal (AMARAL, 1941, p. 90)

Delineando melhor os elementos que comporiam essa inadequação, o autor citou o "vastíssimo território", a "população extremamente diluida e desarticulada econômica e socialmente pelas grandes distâncias" e a sua "incapacidade" na sua "enorme maioria de formar Ideia mesmo confusa dos problemas nacionais". Do que conclui que seria "evidente que o método representativo baseado no sufrágio promíscuo teria de dar forçosamente os mais caóticos resultados" (AMARAL, 1934, p. 158, grifo nosso).

Percebe-se que a critica de Amaral sobre a democracia liberal no Brasil envolvia uma questão central do sistema representativo moderno: a incapacidade de se formar no pais uma opinião pública sobre os assuntos coletivos. Inicialmente, seria tentador concluir que o autor defenderia a tese da "inexistência da opinião pública" no País e, assim, de uma democracia. Todavia, investigando melhor a forma como Amaral aborda o termo opinião pública, percebe-se que a questão não é tão simples, na medida em que esta expressão aparece em diferentes contextos semântico. Com efeito, em certos momentos, como no texto acima, o escritor carioca nos alertava pela impossibilidade de uma opinião pública sobre os assuntos politicamente relevantes. O mais frequente, porém, era afirmar que as manifestações identificadas como a opinião pública nacional eram fruto de "manipulação" (AMARAL, 1930, p. 233-234), o que implicaria no falseamento do próprio sistema representativo. ${ }^{12}$ Em outros momentos, porém, Amaral identifica ou faz uso da ideia de uma opinião pública autêntica no Brasil, mas, contudo, apartada do sistema decisório. ${ }^{13}$

\footnotetext{
10 Não é relevante para a argumentação apresentada nesse artigo uma discussão sobre os conceitos de autoritário e de autoritarismo no período em questão.

${ }^{11}$ É importante, como será feito mais além neste artigo, relativizar - em muito - essa generalização acerca da universalidade dos princípios politicos para todo o liberalismo. Autores cujas obras notoriamente são colocadas no universo do liberalismo político, como Stuart Mill (2007) e mesmo Alexis de Tocqueville (2000), salientam que a democracia, por exemplo, exige condições culturais e comportamentos coletivos - como o senso crítico e o ativismo político - que estão longe de ser universais ou mesmo universalizáveis.

12 Como reforça o autor, ao lembrar que a "grande queixa que, desde os primeiros anos do regime republicano até o momento da deflagração revolucionária de Outubro, foi insistentemente articulada, era a do falseamento do sistema representativo". Diante desta realidade. assevera o Amaral: "A opinião pública encarava as eleições como simples burla, por meio da qual as oligarquias que se sucediam no poder mantinham tanto na União, como nos Estados a continuidade de uma democracia ilusória e desvirtuada" (AMARAL, 1936, p. 156-157).

13 "O aspecto mais grave da degeneração das instituições democráticas no Brasil de antes de 1930 era incontestavelmente a exclusão sistemática e permanente das forças da opinião pública de tudo que se relacionava com a direção da vida nacional e com a solução dos problemas que se apresentavam na administração do país. Ao cabo de perto de quarenta anos de regime republicano, estabelecera-se no Brasil uma separação rigorosa entre o povo e os grupos governantes" (1936, p. 31, grifo nosso).
} 
Nesse caso, porém, ao contrário de falsificada ou inviável, teriamos uma opinião pública, mas distanciada dos grupos governantes. Para o autor, um dos fatores que explicaria esta defasagem entre representantes e representados seria a enorme diferença de recursos materiais e culturais detidos pelas camadas populares em relação à elite política nacional. Todavia, a incapacidade de se formular uma opinião pública autêntica sobre os problemas nacionais seria generalizada: nas massas iletradas, por incompetência e, por parte da elite político-intelectual, por esta manter os olhos e o pensamento voltados para a realidade europeia. Além disso, outra causa dessa dissociação se encontrava nas "dissonâncias babélicas dos psiquismos raciais inassimiláveis, que se contradizem no caldeirão da brasilidade", o que leva o escritor carioca a perguntar: "Como organizar uma democracia com este povo em que se contraditam em colisões violentas os gênios de três raças desviadas pelo destino das orbitas naturais do seu curso evolutivo?" (1934, p. 249-250).

Como retirar uma síntese coerente dessa grande diversidade de usos da expressão opinião pública por Azevedo Amaral e de suas consequências para o pensamento político do autor? Ora, percebemos que, quando o ele fala em opinião pública, não há propriamente uma unidade de definição, podendo esta ser "impossivel", "falsa/falsificada" ou até "autêntica". Da mesma maneira, ela pode, em alguns momentos, estar identificada com opinião esclarecida no sentido de representar a decisão mais sábia para o país e, em outros, como a opinião do maior número, quando o autor igualmente fala em opinião popular (1936, p. 56). Todavia, em todas essas formas, pode-se afirmar que ela nunca esteve presente ou associada positivamente ao sistema representativo democrático liberal existente no Brasil, o qual era sempre entendido por Amaral como falso e/ou apartado dos interesses coletivos. De qualquer maneira, deve-se concluir que a expressão opinião pública é uma constante em seus textos sobre o regime representativo no
País e a sua importância para a legitimidade do mesmo nunca é negada, mesmo nos momentos quando afirma ser ela impossivel ou falsificada.

Tendo em vista essas considerações, surge uma pergunta: seria, para Amaral, a democracia um regime político apenas inadequado à realidade brasileira, mas teoricamente apropriado para outras situações? Ou seria um sistema com problemas intrinsecos que acarretariam o seu fracasso mesmo nos países de origem?

Amaral afirmou na maioria dos seus livros que a democracia funcionou na Europa com significativo sucesso. ${ }^{14}$ Mas, na obra O Brasil na Crise Atual, quando abordou o tema de forma mais detalhada, sua posição foi um pouco diferente. Desde o início da argumentação, o escritor fluminense alerta os seus leitores que "o debate em torno do valor intrínseco da democracia é destituído de caráter realístico", pois, esta questão só seria válida "se todas as sociedades humanas fossem idênticas e muito semelhantes" (1934, p. 240-241). Na sequência, afirmou ainda que a democracia só deu resultados positivos na Europa porque encontrou ai condições ideais para funcionar. Entretanto, ao inquirir sobre estas condições, a resposta de Amaral não deixa de ser surpreendente, embora reveladora de seu pensamento. O autor iniciou sua análise afirmando que "a primeira coisa que impressiona" sobre os países que "se tornaram os modelos do regime democrático, é a homogeneidade étnica e sobretudo uma uniformidade cultural impressionante" (1934, p. 242), o que converge com sua percepção sobre a importância do elemento racial na constituição da organicidade psiquica de uma nação. Na sequência, porém, Amaral, contrariando até o seu próprio princípio da impossibilidade de avaliação intrínseca de um regime político, afirma que a democracia só vigorou na Europa porque pode contar, contraditoriamente, com o senso de hierarquia e de obediência aos superiores que as populações desses países apresentam como condição psíquica espontânea. Desta forma, não surpreende o autor que os regimes democráticos tenham prosperados em países europeus onde

14 "As instituições democráticas têm dado o máximo de resultado na Inglaterra, Suiça, Holanda e nos Paises Escandinavos, vindo em seguida, mas a uma distância apreciável, os Estados Unidos" (AMARAL,1934, p. 241). 
se adota a monarquia e nos quais impera uma "organização social em que as formações aristocráticas asseguram uma hierarquia ainda capaz de resistir às ações corrosivas das forças que lhe são adversas" (1934, p. 244) Concluindo, por fim, que

Somente a mentalidade coletiva em que se criou um automatismo, induzindo à reverencia espontânea dos valores de todas as categorias, pôde adaptar as ideias e os métodos de governo da democracia às exigências disciplinares da ordem social e politica e do funcionamento eficiente dos órgãos políticos e administrativos do Estado (1934, p. 245, grifo nosso).

Disso resultando que a "soberania popular" é uma "ficção", já que o eleitor obediente simplesmente "resigna-se à fatalidade de sua situação pessoal e procura orientar-se por aqueles em que deposita maior confiança e a quem os ligam vínculos mais perceptiveis de interesse e simpatia" (1934, p. 246).

Vê-se, por esta argumentação, que, para Amaral, a democracia liberal apresentava sérios vícios de origem, na medida em que dava margem à desarticulação social, à possivel desobediência à ordem política e à eleição de personalidades "populares" e não necessariamente qualificadas para o exercício das posições de comando. Desta maneira, as condições particulares que permitiam que ela funcionasse nos paises europeus não eram derivadas ou associadas à lógica do próprio regime, mas às características que neutralizam os seus defeitos. Levada para fora desta realidade, a democracia liberal apenas manifestaria os seus efeitos negativos intrinsecos (anarquia, desobediência, incompetência política etc.).

Ora, se estabelecermos relação entre a visão de Amaral sobre o regime democrático e os escritos dos principais teóricos do sistema representativo, veremos que sua argumentação versa a respeito de tópicos e temas muito semelhantes. Tanto esses filósofos quanto Azevedo Amaral compartilham a ideia de que a existência de um regime democrático efetivo depende da presença de uma opinião pública realmente consciente e crítica dos assuntos coletivos. Todavia, enquanto para os pensadores liberais, a apatia e a abstenção política do "povo" seriam um mal que levaria ao despotismo, para Amaral, foram essas carac- terísticas, associadas a uma cultura de disciplina e obediência à hierarquia, que permitiram aos países "democráticos" sobreviver politicamente, mesmo ao custo de contrariar os princípios mais elementares do seu próprio regime. Por outro lado, apesar de defender a necessidade de a elite assumir a direção política de uma nação, Amaral não demonstra preocupação maior com aquilo que os clássicos do liberalismo chamavam de "ditadura das maiorias". Na verdade, para o escritor carioca, essa "ditadura da maioria" não constituía grande ameaça, sendo o maior problema da participação popular o risco de as massas levarem o país à "anarquia" ou à "demagogia".

Para entendermos melhor essa perspectiva do autor, vale salientar melhor a sua percepção para o que ele chama de massas. Seguindo a linha de Le Bon e Gabriel Tarde, Amaral reconhece o valor e a energia política desses grupos, cuja força poderia derrocar qualquer sistema político. Mas, para ele, tais grupos são essencialmente inertes e sua energia só é capaz de produzir efeitos se guiadas por lideranças com projetos políticos claros. Sem lideranças capacitadas, as forças das massas seriam inócuas ou são liberadas para a destruição, sem construir nada de concreto ou duradouro no lugar (1934, p. 166).

Quando Amaral transporta essa análise diretamente ao caso brasileiro, defende que apenas o voto rural controlado pelos grandes proprietários de terra apresentou realmente resultados satisfatórios, pois, "os eleitores da roça, seguindo em matéria eleitoral os seus chefes locais, implicitamente entregam a direção de sua consciência política" (1934, p. 247). O grande problema, para o autor, era que essa realidade social estava mudando drasticamente com o processo de evolução do País para o capitalismo industrial, quando o controlado voto rural estava sendo substituido pelo não controlado voto urbano. Nessa nova realidade, as massas urbanas, instáveis e ignorantes, tenderiam a votar em quem lhe prometia a satisfação de seus interesses imediatos, independentemente da competência política que apresentassem para governar a nação. Fenômeno que, como vimos acima, não era exclusivo do Brasil, mas de todas 
as sociedades capitalistas contemporâneas.

Para organizar essas massas em uma força politicamente atuante, Amaral defendia basicamente duas saídas. A primeira estaria na abolição do voto promíscuo por este ser incapaz de exprimir uma opinião pública realmente verdadeira. Seu interesse não era atacar o conceito de representação popular ou mesmo eliminar o sistema de voto. Ao contrário, o escritor carioca propõe uma nova forma de representação da vontade do "povo" que passaria pelo voto corporativo. Nas palavras do escritor:

[...] para que um processo eleitoral pudesse produzir uma representação mais ou menos autêntica da vontade geral, seria preciso recorrer a um método capaz de permitir a representação dos interesses pelo pronunciamento dos grupos econômicos, que concretizam realidades no conjunto da vida ainda informe da nacionalidade em organização. A representação de classes ou que outro nome tenha e contra a qual se insurgem hoje os que a julgam demasiadamente complexa e adiantada para o nosso estado atual, foi e [continuará] a ser o único processo de relativa eficácia para o estabelecimento de um sistema representativo verídico entre nós $(p$. 1934, p. 158, grifo nosso).

A defesa do corporativismo é listada normalmente como uma das principais diferenças em termos políticos do pensamento de Amaral frente ao liberalismo. Mas, deve-se lembrar, como vimos em Tocqueville, que a preocupação com o excesso de individualismo e de isolamento dos cidadãos já aparece mesmo em autores tidos como liberais. Todavia, no caso de Amaral, não se advoga um total pluralismo dos corpos intermediários como vimos em Tocqueville, mas a sua restrição às divisões de classes com base na posição do indivíduo no sistema produtivos, única capaz de representar os verdadeiros interesses sociais

Por fim, outra diferença que afasta profundamente o pensamento político de Amaral do liberalismo está no papel atribuido pelo autor às
Lideranças políticas, notadamente ao chefe do Executivo, para quem fica o encargo de interpretar e representar na esfera do poder o interesse da coletividade, mesmo à revelia de algumas manifestações espontâneas e esporádicas dessa vontade pelas massas. Nessa linha de argumentação - que tem como referência a liderança autocrática de Vargas a partir do Estado de Sítio em 1935 - , o regime pode prescindir da representação parlamentar para satisfazer a condição básica de qualquer democracia, ou seja, a representação e o atendimento da vontade popular por parte dos detentores do poder. ${ }^{15}$ Em consequência, temos aqui um pensamento que se contrapõe diretamente a qualquer liberalismo político, notadamente de autores como Stuart Mill, para quem somente os diferentes grupos sociais que dividem a sociedade são capazes de expressar as suas próprias vontades publicamente, sendo qualquer forma de "fala pelo outro" uma usurpação.

\section{- Correio da Manhã e a democracia em perigo}

Compreender a percepção do jornal Correio da Manhã sobre a democracia brasileira dos anos 1950 não é tarefa fácil, implicando em muitas questões teóricas e metodológicas, inclusive sobre a (im)possibilidade de se estudar conceitos políticos nas páginas dos jornais. No escopo deste artigo, não teremos condições de abordar estas questões com profundidade, bastando, por ora, apresentar os resultados iniciais de uma investigação mais extensa que estou realizando sobre o(s) sentido(s) com os quais termos como democracia, participação popular e o sistema partidário brasileiro eram empregados nas páginas de opinião do Correio, em especial, nos editoriais. Em um segundo momento, ainda neste artigo, irei comparar as concepções encontradas no impresso

\footnotetext{
15 Sobre o governo autoritário de Vargas correspondendo a uma "verdadeira democracia", podemos ler: "Um dos melhores serviços prestados pelo Presidente Getúlio Vargas consistiu exatamente na obra educativa com que ele começou a preparar uma ambiência adequada à cooperação da opinião pública com o governo na realização de uma verdadeira democracia. A prática de submeter a debate político as medidas projetadas pelo Governo Provisório e os exemplos de alterações feitas em atos já decretados, em conformidade com sugestões julgadas merecedoras de atenção, veio dar ao povo o sentimento da sua autoridade e das suas responsabilidades na orientação da vida nacional. O Governo e a Nação deixaram de ser entidades isoladas. O povo começou a compreender que a sua função no conjunto da vida nacional não era meramente passiva. A ideia de intervenção das forças da opinião pública na direção dos atos do governo surgiu e foi pouco a pouco se desenvolvendo e determinando a criação de uma consciência civica, que não poderá mais ser detida na sua progressiva expansão (AMARAL, 1936, p. 32).
} 
carioca com os tópicos sobre a democracia e seus problemas discutidos na exposição precedente.

Como primeiro ponto a ressaltar, podemos fazer uma avaliação panorâmica a respeito do material já coletado na pesquisa de base, ${ }^{16}$ a partir do qual já é possivel elencar que termos foram os mais frequentes na abordagem da democracia brasileira pelo jornal. Com efeito, nos editoriais selecionados na pesquisa, encontra-se com relativa intensidade o uso de palavras como crise, totalitarismo, comunismo, arcaismo, populismo, massas (ignaras, em alguns casos) e cidadão passivo. Mesmo que ainda não seja possivel fazer afirmações definitivas no estágio atual da investigação, pode-se perceber que a visão geral do jornal sobre a democracia brasileira no periodo é, se não negativa, ao menos preocupante.

Um dos pontos centrais dessa preocupação esteva em um tema básico para os jornais do período, a saber, a "ameaça do comunismo" ao regime democrático e que, assim, não deixa de estar presente no material pesquisado. ${ }^{17}$ Todavia, embora existente, é necessário constatar que o "perigo do comunismo" não foi uma questão muito frequente na abordagem do jornal sobre a democracia brasileira e seus "males". Mais comum do que o comunismo - e, talvez, ainda mais ameaçador do que ele - foi, para o jornal, a presença de Vargas na Presidência da República. Embora o Correio não tenha defendido a impugnação da posse de Getúlio como fizeram outros jornais - $O$ Estado de S. Paulo, por exemplo -, desde o começo do mandato do presidente petebista, o impresso carioca se coloca em vigília, apontando os riscos que Getúlio podia implicar à democracia. Já na nomeação do Ministério de Vargas, podemos ler:
O que importa no Governo do sr. Getúlio Vargas é a escolha que ele fez do ministro da Guerra, porque esta, como escrevemos ontem, seria realmente definidora de seu respeito ou do seu desprezo pelo regime, pelas instituições democráticas em relação às quais sempre houve, da parte do sr. Getúlio Vargas, precedentes de hostilidade e traição (O NOVO..., 1951, p.4).

Para o jornal, Vargas no governo representaria um risco à democracia não só pelo perigo de um novo "golpe de Estado", mas também pelo retorno ao Catete de certas "características" que o presidente teria apresentado ao longo de sua trajetória como governante. Uma delas seria a maneira como Getúlio agia para angariar apoio em torno do seu governo. ${ }^{18}$ Outra, a relação de subordinação com que Vargas impôs ao Legislativo enquanto ocupou o Executivo, tópico muito caro a um pensamento político liberal.

Essa política do presidente transforma o Congresso em mero órgão técnico, reunindo-se só para dar pareceres sobre os projetos do Executivo. Transforma a Câmara dos Deputados em um dos famosos órgãos diretamente subordinados à Presidência da República. [...]

É preciso quebrar os últimos residuos da independência do Parlamento, nome odioso que lembra as prerrogativas dos representantes da Nação Inglesa. É preciso converter as assembleias em órgãos consultivos, mais ou menos à maneira do Soviet Supremo, que sempre aceita as resoluções do Politiburo (Satisfeito..., 1951, p. 4).

Nesse sentido, igualmente não faltou a esta crítica o apelo a outra preocupação típica do pensamento liberal que é a personalização do poder e o risco de despotismo que isto poderia acarretar: "O mal do sr. Getúlio Vargas está em confundir o interesse público com a sua própria pessoa. É o egocentrismo dos temperamentos ditatoriais. Servem-se do povo e jamais cuidam de servi-lo. [...] A lenda de Prometeu acorrentado é o

\footnotetext{
16 Este trabalho inicial da investigação consiste em um levantamento de $1 / 4$ das edições dos jornais envolvidos nessa pesquisa (Correio da Manhã, Jornal do Brasil, O Globo e O Estado de S. Paulo), universo no qual são identificados e classificados todos os editoriais que tratem de temas políticos, em especial quando empregam os termos acima citados. No que se refere ao Correio da Manhã, no exato momento da redação desse artigo, a pesquisa deste jornal já cobriu os anos de 1951 até 1953, sendo que o material coletado ainda está sob análise, do que decorre o caráter parcial dos resultados aqui apresentados.

${ }_{17}$ Como neste editorial onde o jornal apoia a proposta de "medidas de exceção" para combater o "perigo vermelho": "Com os bolchevistas não há possibilidade de discussão ideológica. Não admitem outra opinião. Então, não vamos admitir a deles. [...] São armas que se forjaram em clima de liberdade e que só podem ser empregadas resguardando-se a liberdade das consciências políticas e ideológicas. O respeito à liberdade será o critério da sinceridade do governo no combate ao comunismo" (Combate..., 1953. p. 4).

18 Como fica claro, nesse editorial: "O Sr. Getúlio Vargas, por mais que intelectualmente se esforce para manter-se à altura dos tempos permaneceu, psicologicamente, vinculado a suas experiências anteriores. Conservou, até hoje, a sobrevalorização dos cambalachos de coronéis e das manobras com os empregos e favores públicos. [...] Homem do Estado Novo, conservou as ilusões sobre a eficácia da demagogia trabalhista e das promessas mirabolantes" (Inépcia..., 1952, p. 4).
} 
exemplo mais ilustrativo. Mais ilustrativo, porque eterno (CONTINUE..., 1953, p. 4). Problema que, todavia, o jornal não restringe a Getúlio, mas identifica como um grande mal que aflige o sistema político brasileiro como um todo. ${ }^{19}$

Todavia, a ideia de que a presença de Vargas no governo implicasse obrigatoriamente um risco à democracia pela possibilidade de um golpe de Estado e/ou da hipertrofia do Executivo vai sendo paulatinamente colocada de lado pelo jornal em favor de outra preocupação: a inação do governo e os seus consequentes riscos ao sistema político.

Até que ponto o presidente da República se dará conta de que está se alargando, criticamente, o intervalo entre as atribuições que compete ao Executivo e aquelas que ele efetivamente exerce? [...] Inicialmente supôs-se que o sr. Getúlio Vargas estava preparando um golpe maquiavélico. [...] Mas já não se atribui a inércia do governo a causas tão misteriosas e complexas, senão que se as entende como produto da pura e simples omissão do Executivo. E é o próprio Legislativo, tão cioso de suas franquias, tão facilmente suspicaz em relação ao Executivo quem, agora, se preocupa em assegurar um governo (GOVERNO..., 1953, p. 4, grifo nosso).

Para o Correio, desta inação de Vargas poderiam advir grandes dificuldades ao regime democrático nacional. Vejamos duas passagens interessantes acerca desse tema:

Na verdade, o Sr. Getúlio Vargas, por desorientação e falta de energia, está deixando o poder the escapar das mãos. Ou o presidente põe termo à intriga política - conservando ou remodelando o Ministério, mas em qualquer caso resumindo a chefia do governo - e desemperra a administração, ou corre o risco de lançar o país na anarquia (Às vésperas..., 1952, p. 4. grifo nosso).

[...]

o que muito se temia, a principio, que o sr. Getúlio Vargas, com o vezo da ditadura, tornasse a investir contra o regime democrático, para substituí-lo, foram vãos temores. Nem por isso, como proclamam as classes conservadoras, as instituições deixam de estar em perigo, correndo o risco (ilegivel) comunista em posto de relevo na administração. E com o país sob o peso da crise econômica e social que, de ano para ano, se aprofunda em descontentamento e desagregação, na desordem dos serviços públicos, na carestia e na indisciplina.

As instituições continuam jurídica e politicamente intocadas; mas o vazio no governo contamina a sua melhor substância (AS INSTITUIÇÕES..., 1953, p. 4).

Esses trechos são bons indicativos da mudança na percepção do Correio sobre o governo Vargas, transitando do risco do retorno à ditadura para o temor da desagregação social decorrente não da ação, mas da inação de Getúlio. É importante reter esse ponto - que será muito recorrente no jornal a partir de meados de $1951^{20}$ - na medida em que ela revela uma percepção crítica não apenas sobre o governo Vargas, mas também em relação a regime democrático brasileiro do período. Em outras palavras, não preocupa o Correio apenas a "carência de governo", mas também uma "carência de todo o sistema representativo". Em um editorial de outubro de 1953. intitulado exatamente "Crise dos Partidos", o jornal diz abertamente o seguinte:

Vista do ângulo isento e objetivo do cientista político, a atual crise da democracia brasileira se caracteriza essencialmente como uma crise de partidos. Na verdade, o regime democrático não pode funcionar normalmente a não ser quando as organizações partidárias refletem adequadamente a infraestrutura política do país. O que está ocorrendo hoje. no Brasil, é exatamente um grande desajustamento entre os nossos partidos políticos e as novas realidades do meio político-social brasileiro (CRISE..., 1953, p. 4). ${ }^{11}$

Em outro editorial, ainda de 1953, podemos ler este "diagnóstico" geral da realidade política brasileira:

O que torna especialmente grave a situação brasileira e exaspera as consequências das dificuldades econômicas e sociais que o país está experimentando é o fato de se verificar, em nossas instituições politicas, um profundo divórcio entre sua aparência e sua realidade. Há um governo e uma oposição aparentes, dis-

\footnotetext{
19 "Há um vício nos homens de governo do Brasil, vício que vem de longe, mas que se exacerba quando o sr. Getúlio Vargas está no poder: é o personalismo. Embora democrático seja o regime e, portanto, maiorias e minorias tenham direitos iguais, insistem os governantes em não reconhecer esse princípio fundamental, o que nos leva a crer que muitos deles ainda estão na fase de educação política primitiva, em que se dividia o povo em senhores e escravos (Personalismo..., 1952, p. 4).

${ }_{20}$ Sobre isso, podemos elencar uma série de editoriais distribuidos ao longo do periodo que está sendo pesquisado ilustrando a presença do tema em questão: INÉPCIA..., 1952, p. 4; ȦS VÉSPERAS..., 1952, p. 4; A SEGUNDA..., 1952, p. 4; e AS INSTITUIÇÕES..., 1953, p. 4. ${ }_{21}$ Análise semelhante podemos encontrar em: SIGNIFICADO...,1951, p. 4 e CREPÚSCULO..., 1951, p. 4.
} 


\begin{abstract}
tintos e diversos das forças que efetivamente estão interferindo nos acontecimentos. Há uma luta entre o governo e a oposição nominais que encobre as verdadeiras lutas que atualmente se processam. Este fato, no entanto, ainda não foi compreendido pela opinião pública. (APARÊNCIA... 1953, p 4, grifo nosso).
\end{abstract}

Ora, estamos aqui diante de um problema grave em se tratando de um regime classificado como democrático-liberal. Deficiências no sistema representativo foi apontado como um dos maiores riscos à democracia política por parte de autores como Azevedo Amaral, mas que também gerariam desconfortos entre os clássicos do liberalismo, como Tocqueville e Stuart Mill. Além do mais, tal problema não pode ser reduzido ou considerado como resultado da ascensão de Vargas ao poder da República, na medida em que este editorial - assim como os demais já citados - estende a crítica também às outras forças políticas, notadamente a UDN (União Democrática Nacional), que exerceriam uma "oposição nominal e aparente". Sendo o Executivo e o Legislativos meras "ficções", a consequências é que as reais forças políticas passam a se exercer fora do universo representativo, como fica claro nessa passagem: "A verdadeira oposição são as massas que elegeram o sr. Jânio Quadros e se agitam em greves. E são as classes conservadoras, estranguladas pela CEXIM e pela política financeira do governo."

Tal diagnóstico do sistema representativo brasileiro dos anos de 1950 não poderia ficar sem maiores consequências, como indica o próprio jornal no trecho que finaliza o seu texto:

Dai o caráter gravíssimo dos atos que se processam no under ground politico e social. Porque é uma fatalidade política o caminharem as forças reais para se tornarem institucionais. E essa transformação significa no momento golpe ou revolução APARENCIA. 1953, p 4, grifo nosso).

Como poderíamos avaliar o posicionamento do jornal frente a este diagnóstico? Seria uma visão negativa identificando e/ou prevendo a falência do regime democrático no Brasil e, assim, da própria democracia? Ou estaríamos diante de uma percepção da eminência de uma profunda mudança politica, na qual as "verdadeiras forças sociais" poderiam assumir o controle do país?

É difícil responder a estas questões no atual estágio da investigação, mas alguns elementos já identificados na pesquisa permitem fazer certas inferências, mesmo que ainda provisórias. Por exemplo, em um editorial em que trata de problemas no diretório do PTB, o jornal afirma o seguinte:

Foi ultrapassada, no Brasil, a época da política de clientela. As forças sociais, cada vez mais conscientes da importância da ação política, estão maduras para se arregimentarem de baixo dos partidos capazes de representar e orientar suas aspirações. Não é outro o motivo do sucesso dos demagogos junto às massas. Não é outra a razão pela qual certos aventureiros conseguem empolgar as classes produtoras. Proletários e burgueses, consumidores e produtores, os grandes grupos em que se divide a comunidade brasileira, necessitam de uma politica de base ideológica. Mas, na ausência de verdadeiros partidos e verdadeiros líderes, são arrebanhados pela contrafação dos demagogos e aventureiros.

A crise do PTB, mais do que um episódio partidário, é um aspecto da crise política brasileira: a nação está ficando madura para a vida pública, mas faltam os dirigentes." (A CRISE..., 1952, p. 4. grifo nosso).

O texto acima apresenta novos elementos para a discussão em curso. Com efeito, encontramos novamente os temas da presença de "forças sociais" capazes e propensas à ação política e da ausência de "verdadeiras lideranças", mas agora o texto deixa mais clara uma outra questão: a tendência das forças sociais, em parte classificadas como "massas", de serem arregimentadas politicamente por "demagogos" e "aventureiros" diante das deficiências do sistema representativo. Embora o jornal elenque nesses textos tanto as massas, quanto a burguesia como forças sociais cujas aspirações não são atendidas pelos sistema representativo, são as "massas descontentes" as que merecem mais e constante atenção por parte dos editorialistas do Correio. Em uma passagem bem ilustrativa, o jornal fará o seguinte comentário sobre a supressão de uma mobilização popular comemorativa do segundo ano do governo Vargas:

Mais do que com manifestações, sobre cujo valor, aliás, o sr. Getúlio Vargas não se ilude, o presidente da República se preocupa em atingir resultados 
mais objetivos. Tem consciência do terrivel desgaste que sofreu nestes dois anos de governo, tanto como líder carismático das massas como na sua posição mesma de chefe de governo. Cansaram-se as massas de promessas e de discursos. E seguindo a inexorável dialética da demagogia ultrapassaram o próprio demagogo e exigem espetáculo novo e mais audacioso (A EXPERIÊNCIA..., 1953, p. 4, grifo nosso)

Percebe-se, nessa passagem, claramente qual é o maior ponto de inquietação do Correio com a "ausência" de governo e de "verdadeiras lideranças políticas": enquanto estes se omitem ou fracassam, as massas se mobilizam e ultrapassam os seus próprios "agitadores". Em outros momentos, porém, vemos essa "agitação das massas" ser colocada como uma consequência da própria ação de Vargas em uma busca desesperada de popularidade.

Enquanto isso, ruge descontentamento Massas primárias, a que se tem negado a mais elementar instrução e às quais se nega, agora, a própria subsistência, começam a dar os primeiros sinais de que se aproxima a explosão. E o Sr. Getúlio Vargas não vê o vulcão que se forma por baixo de seus pés, profere discursos incendiários, concitando 0 operariado a participar do governo, sem ter nenhuma ideia de como tal pudesse se realizar.

Nem se concebe que, numa fase de inquietação social, um homem que já se encontra na Presidência da República e no fim de sua carreira politica vá promover agitação de massas por insensato apego à popularidade (ȦS VÉSPERAS...,1952, p. 4)

Ou seja, quer por "inação", quer por uma "ação irresponsável", a presença de Vargas no governo está associada a esta perigosa mobilização das "massas primárias". Todavia, como já aconteceu na questão das deficiências do sistema representativo, esse risco de ascensão das "massas" não é um problema derivado exclusivamente da eleição de Vargas à Presidência da República. Vejamos dois pequenos trechos nos quais a questão é abordada. O primeiro, diz respeito a uma proposta de reforma do ensino no Segundo Governo Vargas pelo ministro da Educação e Saúde, Ernesto Simões Filho:

Os efeitos desta apatia e desorientação já se fazem sentir. São as massas, a quem se deu o sufrágio universal e secreto sem a correspondente educação, que precipitam o país no vórtice da demagogia. [...]
Que se faz para remediar este descalabro? $\mathrm{Na}$ verdade, o governo ainda não percebeu o problema. E tão tranquilo anda o ministro da Educação que, pela recente portaria 301, resolveu abaixar as notas minimas necessárias à aprovação e adotou outras medidas para facilitar a vadiagem dos estudantes (ECONOMIA..., 1952, p. 4).

O outro editorial versa sobre a necessidade de os governantes do país agirem de forma mais criativa e planejada. Criticando essa "falta de criatividade", argumenta:

\begin{abstract}
A mesma falta de imaginação criadora leva as elites de nossos dias a sucumbir diante da outra dimensão de nossa crise: a rebelião das massas. Em face dessas massas miseráveis e ignaras, carentes de pão e de espíritos, não temos sabido apresentar outro caminho senão o da demagogia fácil, que saca sobre a parca riqueza acumulada, queimando, numa euforia dos momentos, todas as reservas do futuro (IMAGINAÇÃO..., 1952, p. 4).
\end{abstract}

Por esses trechos acima, percebe-se claramente como o diagnóstico do jornal acerca da "saúde" institucional do regime democrático brasileiro dos anos de 1950 vai muito mais além de uma simples condenação da vitória eleitoral de Vargas. Mesmo que a presença de Getúlio no poder seja um forte sintoma dos defeitos do regime, a argumentação do periódico para ilustrar essa questão ultrapassa a mera condenação do getulismo e dos seus "males". Ao contrário, Getúlio e toda as deficiências de nosso sistema representativo são frutos de um mal maior para o qual, parece, ainda não conseguimos dar uma solução: a ascensão das "massas ignaras", sem "pão e sem espírito", a quem se deu o "sufrágio universal e secreto sem a devida educação".

Como entender este diagnóstico do Correio e as suas consequências para a sua visão da democracia brasileira nos anos de 1950? O estágio atual da pesquisa não permite ainda conclusões definitivas, embora seja possivel levantar algumas hipóteses a serem verificadas ao longo da investigação.

Um ponto importante seria analisar, pelo que vimos na parte anterior, quais os efeitos do diagnóstico negativo do jornal sobre o sistema político brasileiro para a formação de uma verdadeira opinião pública no País, condição necessária 
de uma democracia efetiva. Em relação a este ponto, curiosamente, nos editoriais até agora selecionados para a pesquisa, o tema da opinião pública não merece grande destaque. A expressão opinião pública é encontrada, mas normalmente como elemento retórico a partir do qual o periodo procura fazer algum contraponto ao universo político. ${ }^{22}$ Todavia, em um editorial no qual avalia a "baixa" qualidade do Legislativo nas principais democracias ocidentais, o Correio afirma que "o Parlamento - e isso é particularmente verdadeiro no caso do Brasil - nem re-

presenta a opinião pública, nem é composto na média dos seus membros, por pessoas à altura dos encargos legislativos". E, depois de elencar as "três classes de pessoas" que comporiam a Congresso Nacional - os "demagogos" (também chamados de "elite da ralé social"), os "plutocratas" e a "oligarquia rural", afirma:

É evidente que estas três classes de pessoas, como dissemos, nem podem representar a opinião pública, nem podem estar à altura de suas atribuições. A opinião pública é a expressão da opinião sobre as coisas públicas. Não a formam, portanto, as pessoas incapazes de ter qualquer opinião sobretudo sobre as coisas públicas (A CRISE...,1952, p. 4, grifo nosso).

No fim do texto, o jornal ainda conclui afirmando que "em profundidade, a elevação do nivel do Congresso depende de uma reforma de base nas instituições, que impliquem em critérios objetivos para a seleção dos legisladores". Todavia, não revela que reforma seria esta e nem quais seriam os "critérios objetivos" de escolha dos parlamentares, ficando a inquirição sobre o tema tarefa a ser realizada posteriormente.

Encerrando esta análise, é importante relacionar este levantamento das posições do Correio com a discussão conceitual que fizemos no início. Nesse sentido, devemos apontar que a preocupação com predomínio das "massas ignaras" na política brasileira pode encontrar similitudes na obra dos teóricos da democracia liberal, quando estes demonstram o seu temor acerca da "ditadura/tirania da maioria". Todavia, a leitura que fizemos dos editoriais do Correio da Manhã até agora permite perceber uma compreensão dos problemas políticos brasileiros que ultrapassa os receios originais desses autores. Com efeito, tanto para Mill, quanto para Tocqueville, a maior preocupação com o risco da tirania da maioria era a ameaça à liberdade individual e o sufocamento das minorias que ela poderia acarretar. As principais saidas para isso, em ambos os autores, estavam: a) na preservação de corpos intermediários que mantivessem os cidadãos sempre mobilizados e interessados nos assuntos públicos e b) na elaboração de mecanismos institucionais que permitissem a maior diversidade possivel de participação política, especialmente no que se refere à livre expressão e a autorrepresentação das minorias, entendidas aqui como as elites cuja existência política se via ameaçada pelos regimes de maioria simples.

No caso do Correio, porém, embora as preocupações com a liberdade individual e com o risco de sufocamento das elites estejam presente, o termo massa empregado pelo impresso e seus perigos para a democracia não podem ser entendidos apenas como equivalentes aos das maiorias com baixo nivel intelectual. A vertente teórica é outra e, como já vimos em Amaral, dialoga com autores como Le Bom e Splenger e, no caso específico do Correio, com o filósofo espanhol Ortega Y Gasset. Esses autores, de diferentes formas, teorizaram sobre as sociedades ditas de "massa" e o fenômeno do comportamento político do "homem em multidão", bem como a respeito dos efeitos desse processo para o "igualitarismo" e o "rebaixamento cultural" das sociedades contemporâneas. A própria expressão "rebelião das massas" que aparece em um dos editoriais do Correio é o título de uma das principais obras de Ortega Y Gasset sobre o tema, onde o filósofo desenvolve sua visão negativa da ascensão do

22 Ao criticar uma Mensagem de Vargas ao Legislativo, o jornal disse: "No fundo, todas as correntes da opinião pública, dentro e fora do Congresso, julgam a Mensagem mais uma peça literária e inútil" (MENSAGEM...1953, p. 4). Em relação à UDN, por exemplo, lembrando a quantidade de votos que o Brigadeiro Eduardo Gomes recebeu na campanha de 1950, afirma: "A UDN nem sempre esteve à altura de interpretar e valorizar esse movimento da opinião pública, nem sempre compreendeu e zelou estritamente por este patrimônio de esperanças de milhões de brasileiros, correspondendo e acudindo aos que the confiavam a sua vocação patriótica" (CREPÚSCULO... 1951, p. 4). 
"homem-massa" como força política. ${ }^{23}$ Embora não tenhamos condições aqui de retomar os argumentos desses autores - tema que será objeto de outro estudo, trabalhando especificamente o conceito de "massa" nos jornais cariocas dos anos de 1950 -, devemos lembrar que a sua visão geral sobre a democracia é bem mais negativa daquela sustentada pelos intelectuais liberais do século XIX e seus efeitos bem menos reversiveis por reformas institucionais dentro do regime. Mesmo que este tópico deva ser melhor investigado, o Correio parece compartilhar muito desta visão "negativa", como podemos ver em um editorial apoiando a destinação de verbas para o Museu de Arte Moderna do Rio de Janeiro, onde se afirma:

Atravessa a nossa civilização uma fase histórica pouco propícia às atividades culturais. $O$ utilitarismo vitorioso, cujo espírito, ou melhor, antiespírito (sic) já se infiltrou em todos os regimes não tolera esforços científicos ou artísticos que não sejam de imediata aplicabilidade prática. As elites aristocráticas desapareceram. As da classe média, que foi, durante o século XIX, o portador principal do progresso cultural, estão materialmente enfraquecidas e, ao mesmo tempo, contaminadas pela vulgaridade, que inspira integralmente as massas, os verdadeiros donos dessa época (O VOTO...,1952, p. 4. grifo nosso).

Em consequência, os argumentos desenvolvidos pelo Correio para analisar a realidade da democracia brasileira dos anos de 1950 parecem se aproximar bem mais daqueles desenvolvidos por Azevedo Amaral, nos anos de 1930. Vimos como este autor faz amplo apelo ao conceito de massa quando analisa a politica nacional e localiza na ascensão das massas uma das forças que impelem o país para um regime autoritário: poderosas, instáveis e incapazes de se auto governarem, as massas exigem lideranças políticas fortes e intelectualmente superiores a elas, caso contrário, caímos nos governos manipuladores do "povo" ou no total desgoverno. Para o Correio, "entregue a si mesmas, as massas brasileiras voltaram-se para o comunismo e para a demagogia trabalhista" (CRISE...,1953, p. 4). E, em ambos os casos, apenas as elites podem resolver o problema, ao assumir o papel de direção do país. Como lembra o jornal:

A situação a que chegou o país, crivado de problemas de organização e de administração, e as perspectivas que se the abrem [...] levam a maioria das gentes a um apelo às "elites". capazes de conjurar o que há de negativo em nosso sistema de vida e de promover o desenvolvimento cultural e econômico que se encontra na possibilidade e no destino do Brasil (ELITES..., 1953, p. 4)

Por fim, é importante frisar que vários aspectos separam o pensamento de Azevedo Amaral dos anos de 1920/30 das ideias defendidas pelo Correio nos anos de 1950, para além da própria distância temporal de 20 anos. A começar pelo papel oposto que ambos atribuem a figura de vargas no universo político nacional - embora, seja necessário lembrar que a valorização positiva de Getúlio só aparece tardiamente na obra de Amaral, na segunda metade dos anos de 1930. Ademais, Azevedo Amaral é declaradamente um forte crítico da democracia liberal, enquanto o impresso carioca - ao menos no universo pesquisado - não demonstra ser um crítico do regime democrático em si mesmo. De qualquer maneira, os diagnósticos apresentados em épocas diferentes sobre os males da democracia brasileira são muito semelhantes (predominância das massas ignaras, falência do sistema representativo, fracasso das elites dirigentes), bem como algumas soluções (necessidade de as elites assumirem seu papel de direção das massas) muito parecidas para serem simplesmente negligenciadas.

Entretanto, depois deste diagnóstico, a resposta à questão sobre qual seria a posição do jornal a respeito da viabilidade do regime democrático nos termos em que ele se encontrava nos anos de 1950 ainda depende do avanço da investigação agora em curso.

\footnotetext{
${ }_{23}$ Nessa obra, podemos ler, por exemplo: "Há um fato que, para bem ou para mal, é o mais importante na vida pública europeia da hora presente. Este fato é o advento das massas ao pleno poderio social. Como as massas, por definição, não devem nem podem dirigir sua própria existência, e menos reger a sociedade, quer dizer-se que a Europa sofre agora a mais grave crise que a povos, nações, culturas, cabe padecer. Esta crise sobreveio mais de uma vez na história. Sua fisionomia e suas consequências são conhecidas. Também se conhece seu nome. Chama-se a rebelião das massas" (ORTEGA Y GASSET, 1987, p. 17).
} 


\section{Referências}

AMARAL, Antônio José de Azevedo. O Estado Autoritário e a Realidade Nacional. Rio de Janeiro: José Olympio, 1938.

AMARAL, Antônio José de Azevedo. Getúlio Vargas Estadista. Rio de Janeiro: Irmãos Pongetti Editores, 1941.

AMARAL, Antônio José de Azevedo. O Brasil na Crise Actual. São Paulo: Companhia Editora Nacional, 1934.

AMARAL, Antônio José de Azevedo. Ensaios Brasileiros. Rio de Janeiro: Omena \& Barreto, 1930.

Amaral, Azevedo. Renovação Nacional. Rio de Janeiro: Imprensa Nacional, 1936.

Bobbio, Norberto. Teoria geral da política: a filosofia politica e as lições dos clássicos. Rio de Janeiro: Campus, 2000.

CHAMPAGNE, Patrick. Faire l'opinion. Le nouveau jeu politique. Paris: Minuit, 1990. (Coleção Le Sens Commun).

Constant, Benjamin. Da liberdade dos antigos comparada à liberdade dos modernos. In: Constant, Benjamin et al. Filosofia Politica. Porto Alegre: L\&PM Editores, 1985. v. 2.

HABERMAS, Jürgen. Mudança Estrutural na Esfera Pública: Investigações quanto a uma categoria da sociedade burguesa. n. 76. Rio de Janeiro: Tempo Brasileiro, 1984. (Biblioteca Tempo Universitário, Série Estudos Alemães).

HOBBES, Thomas. Leviatã. São Paulo: Martins Fontes, 2003 [1651].

MILL, John Stuart. Ensaio sobre a Liberdade. São Paulo: Editora Escala, 2007.

Mossé, Claude. As instituições gregas. Lisboa: [s. n.], 1985.

ORTEGA Y GASSET, José. A Rebelião das massas. Martins Fontes: São Paulo, 1987.

OSTRENSKY, Eunice. Soberania e representação: Hobbes, parlamentaristas e levellers. Lua Nova, São Paulo, n. 80, p. 151-179, 2010. https://doi.org/10.1590/ S0102-64452010000200007.

PITKIN, Hanna Fenichel. Representação: Palavras, Instituições e Ideias. Lua Nova, São Paulo, n. 67, p. 263-269, 2006. https://doi.org/10.1590/S010264452006000200003.

ROSANVALLON, Pierre. Le sacre du citoyen Histoire intellectuelle du suffrage universel en France. Paris: Gallimard, 1992.

TOCQUEVILLE, Alexis de. A democracia na América: sentimentos e opiniões: de uma profusão de sentimentos e opiniões que o estado social democrático fez nascer entre os americanos. São Paulo: Martins Fontes, 2000.

\section{Fontes Primárias}

A CRISE do Legislativo. Correio da Manhã, Rio de Janeiro, p. 4, 26, jan. 1952. Primeiro Caderno.

A CRISE do PTB. Correio da Manhã, Rio de Janeiro, p. 4, 23 maio 1952. Primeiro Caderno.

A SEGUNDA fase. Correio da Manhã, Rio de Janeiro, p. 4. 5 out. 1952. Primeiro Caderno.
ÀS VÉSPERAS da anarquia. Correio da Manhã, Rio de Janeiro, p. 4, 28 set. 1952. Primeiro Caderno.

AS INSTITUIÇÕES e o governo. Correio da Manhã, Rio de Janeiro, p. 4. 15 jan. 1953. Primeiro Caderno.

COMBATE ao Comunismo. Correio da Manhã. Rio de Janeiro, 12 fev. 1953. Primeiro Caderno.

CONTINUE nesse rumo. Correio da Manhã, Rio de Janeiro, p. 4. 09 set. 1953. Primeiro Caderno.

CREPÚSCULO dos Partidos. Correio da Manhã, Rio de Janeiro, p. 4, 20 fev. 1951. Primeiro Caderno, p. 4

CRISE dos Partidos. Correio da Manhã, Rio de Janeiro, p. 4, 28 ago. 1953. Primeiro Caderno.

ELITES. Correio da Manhã, Rio de Janeiro, p. 4, 03 fev. 1953. Primeiro Caderno.

GOVERNO e desgoverno. Correio da Manhã, p. 4, Rio de Janeiro, 18 mar. 1953. Primeiro Caderno.

IMAGINAÇÃO criadora. Correio da Manhã. Rio de Janeiro, p. 4, 28 ago. 1952. Primeiro Caderno.

INÉPCIA política. Correio da Manhã, Rio de Janeiro, p. 4, 21 jun. 1952. Primeiro Caderno.

MENSAGEM de Ninguém. Correio da Manhã. Rio de Janeiro, p. 4, 17 mar. 1953. Primeiro Caderno.

O NOVO Ministério. Correio da Manhã, Rio de Janeiro, p. 4, 01 jan. 1951. Primeiro Caderno.

O VOTO. Correio da Manhã, Rio de Janeiro, p. 4, 10 out. 1952. Primeiro Caderno.

PERSONALISMO, Correio da Manhã, Rio de Janeiro, p. 4. 09 mar. 1952. Primeiro Caderno.

SATISFEITO, Correio da Manhã, Rio de Janeiro, p. 4, 08 ago. 1951. Primeiro Caderno.

SIGNIFICADO das Eleições. Correio da Manhã, Rio de Janeiro, p. 4, 24 out. 1951. Primeiro Caderno.

\section{Luís Carlos dos Passos Martins}

Pós-doutor em História pela Pontificia Universidade Católica do Rio Grande do Sul (PUCRS, Porto Alegre, RS, Brasil), professor adjunto e coordenador do Curso de Graduação em História e professor do quadro permanente do Programa de Pós-graduação em História da PUCRS.

\section{Endereço para correspondência}

Luis Carlos dos Passos Martins

Pontificia Universidade Católica do Rio Grande do Sul Av. Ipiranga, 6.681, Prédio 8/9, sala 1.

Partenon

97010-082

Porto Alegre, RS, Brasil 